\title{
サイジング剤に添加した黒鉛微粉末による炭素／ 炭素複合材料のマトリックス組織制御
}

安田榮一·田辺靖博·高畠 稔*

(平成元年 7 月 4 日受理)

\section{Control of Matrix Microstructure in Carbon Fiber/Pitch derived Carbon Composite by Ultra Fine Graphite Powders in Sizing Agent}

\author{
Eiichi Yasuda, Yasuhiro Tanabe and Minoru Takabatake* \\ Research Laboratory of Engineering Materials \\ Tokyo Institute of Technology \\ 4259, Nagatsuta, Midori, Yokohama 227, JAPAN \\ *New Material Div. \\ Petoca Co., Ltd. \\ Kashima, Ibaraki 314-02, JAPAN
}

\begin{abstract}
Matrix microstructure in carbon fiber/carbon composite of pitch derived carbon could be changed into fine structure using graphite fine powder ( $1 \mu \mathrm{m}$ under) added carbon fiber on it. The matrix in the composite changed into fine mosaic structure, and the bending strength of the composite increased compared with that of composite with fibers having no-graphite particles.
\end{abstract}

KEYWORDS: C/C composite, graphite powder on carbon fiber, Matrix control, Mechanical Property

\section{1. はじめに}

ピッチは, 炭素繊維/炭素複合材料のマトリックス前 駆体として用いられている。しかし，一般にピッチマト リックスは熱処理を施すととにより配向し, 層状となる。 層状組織は, 一般に層間せ九断強度が低く, 強度を必要 とする炭素繊維/炭素複合材料のマトリックス組織とし ては不向きであると考えられる ${ }^{1)}$ 。乙れに対しファイン モザイクをマトリックス組織とする複合材料は, 高い強 度を発現する ${ }^{1)}$ 。マトリックスを微細化する方法として, 分別ピッチあるいは混合ピッチ ${ }^{1)}$ を用いる方法, ピッチ 飞黒鉛微粉末 ${ }^{2}$ または硫黄 ${ }^{3)}$ を添加する方法が考えられ

東京工業大学 工業材料研究所： $\mathbf{\top} 227$ 横浜市緑区長津 田 4,259
る。しかし，前者は製造工程が煩雑であり，また後者は 繊維のフィルター効果により添加黒鉛微粉末が充分に含 浸されないことがある。

そこで, 本研究では予め黒鉛微粉末を塗布した繊維を 用いることにより，マトリックスを微細化する新しい方 法について検討した。加えて，本方法で作製した炭素緎 維 / 炭素複合材料の機械的性質について考察した。

\section{2. 実験方法}

用いた炭素繊維は， $2500^{\circ} \mathrm{C}$ 処理した石油ピッチ系炭 素緘維 (KC-25, ペトカ製) である。マトリックスピッ 于前駆体には，LP-280(ペトカ製) を用いた。主な物性

*(株)ペト 新素材事業部 : ₹ 314-02 茨城県鹿島郡 神栖町東和田 4 
を Table 1 亿示す。

炭素繊維をコロイダル黒鉛 (1 1 m $\mathrm{m}$ 以下) とイソプロパ ノール混合液 (DAG 154; Acheson Colloids Co.体積 比 1 : 2) に浸し, フィラメントワインディング法により マンドレルに一方向に揃えて巻取った。イソプロパノ一 ルのみの溶液に含浸して同様にして巻取ったものを比較 用として用いた。

溶融したピッチ中 $\left(235-240^{\circ} \mathrm{C}\right)$ に巻取った炭素繊維

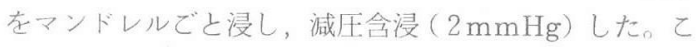
の複合材料をオートクレーブ中 $\left(650^{\circ} \mathrm{C}, 15 \mathrm{MPa}\right)^{2)}$ で

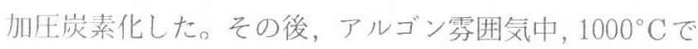
熱処理を行い，更にオートクレーブ中で再含浸処理を 2 回行った。その後, 必要に応じて高温熱处理を施した。 炭素繊維の体積含有率は，何れの場合む約50\%であった。

繊維軸長手方向に沿って強度試験片を切り出し( $50 \times 5$ $\left.\times 1.25 \mathrm{~mm}^{3}\right)$ ，4点曲げ法 $(40 \mathrm{~mm}$ 外部スパン, $13.3 \mathrm{~mm}$ 内部スパン)により曲げ強度を測定した。

Table 1 Properties of (a) carbon fiber and (b) pitch used in this study.

\begin{tabular}{ll}
\hline (a) Tensile Strength & $1.91 \mathrm{GPa}$ \\
Tensile Modulus & $255 \mathrm{GPa}$ \\
Number of Filament & 2000 \\
Heat-treatment Temperature & $2500^{\circ} \mathrm{C}$ \\
\hline (b) Softening Point & $141.5^{\circ} \mathrm{C}$ \\
Fixed Carbon & $58.7 \%$ \\
Toluene Insoluble & $25.7 \%$ \\
Quinoline Insoluble & $3.1 \%$ \\
Sulfur & $0.15 \%$ \\
\hline
\end{tabular}

\section{3. 結果亡考察}

黒鉛微粉末塗布炭素絨維老用いた炭素/炭素複合材料 ( $\mathrm{KCG} / \mathrm{C}$ 複合材料) ならびに末塗布繊維を用いた炭素/ 炭素複合材料 ( $\mathrm{KC} / \mathrm{C}$ 複合材料) $02500^{\circ} \mathrm{C}$ 熱処理後の偏 光顕微鏡写真在 Fig. 1 亿示す。 $\mathrm{KC} / \mathrm{C}$ 複合材料のマト リックス組織が流れ組織であるのに対して, $\mathrm{KCG} / \mathrm{C}$ 複 合材料のマトリックス組織は微細化し, 全体に渡ってモ ザイク組織となった。

密度, 開気孔率, 曲げ強度, 曲げ弾性率を Table 2 亿, 応力一歪曲線 (S-S 曲線), 破面の SEM 写真を Fig. 2 に示す。密度, 開気孔率ともに試料間で大きな差は無か った。 $\mathrm{KCG} / \mathrm{C}$ 複合材料は, 何れの熱処理温度でも $\mathrm{KC} /$ $\mathrm{C}$ 複合材料に比べ高い強度を示した。熱処理温度 $1000^{\circ} \mathrm{C}$ の $\mathrm{KC} / \mathrm{C}$ 複合材料 ( $\mathrm{KC} / \mathrm{C}-10)$ 怔脆性的な破壊をした のに対して, KCG/C 複合材料 (KCG/C-10) は破面で の繊維の引き抜けが認められ, 階段状の S-S 曲線を示
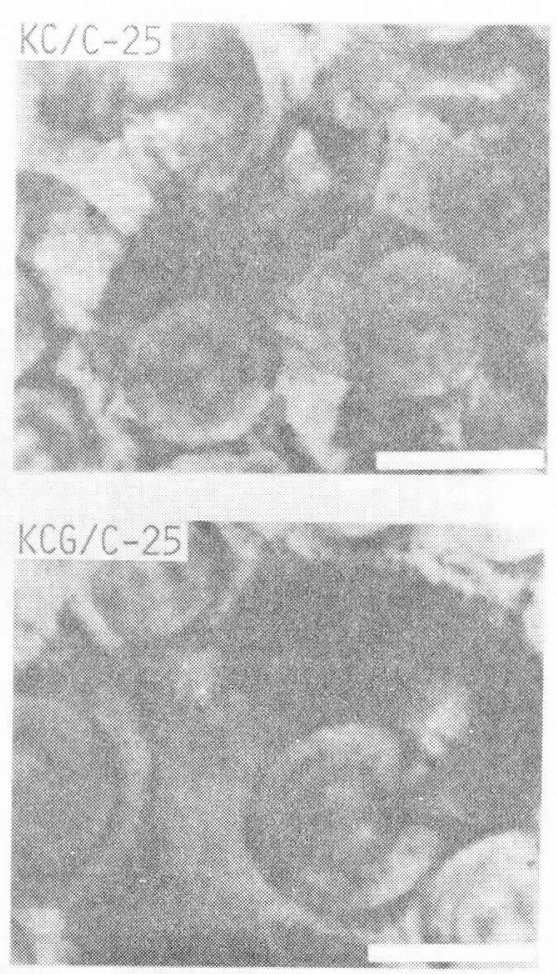

Fig. 1 Typical micrographs of $\mathrm{KC} / \mathrm{C}-25$ and KCG/C-25 composites. bar: $10 \mu \mathrm{m}$

Table 2 Density, porosity and mechanical properties of carbon fiber/carbon composites.

\begin{tabular}{ll|rrr|rcr}
\hline & & \multicolumn{3}{|c|}{ KC/C- } & \multicolumn{3}{c}{ KCG/C } \\
& & 10 & 20 & 25 & 10 & 20 & 25 \\
\hline $\begin{array}{l}\text { Heat-treatment } \\
\text { Temperature }\end{array}$ & $\left({ }^{\circ} \mathrm{C}\right)$ & 1000 & 2000 & 2500 & 1000 & 2000 & 2500 \\
$\begin{array}{l}\text { Bulk Density } \\
\text { Open Porosity }\end{array}$ & $\left(\mathrm{g} / \mathrm{cm}^{3}\right)$ & 1.68 & 1.82 & 1.74 & 1.79 & 1.77 & 1.81 \\
$\begin{array}{l}\text { Flexural } \\
\text { Strength }\end{array}$ & 10.0 & 7.2 & 13.8 & 7.0 & 12.5 & 9.2 \\
$\begin{array}{l}\text { Flexural } \\
\text { Modulus }\end{array}$ & $(\mathrm{MPa})$ & 496 & 667 & 453 & 737 & 913 & 586 \\
\hline
\end{tabular}

した。 KC/C-200 S-S 曲線は, 最大荷重に達した後は 階段状となり，破断面には繊維束の引き抜けが観察され た。 KCG/C- 20 では, 最大荷重付近で S-S 曲線の傾き が緩やかになり始め, 最大荷重後も階段状と言うよりは 連続的に減少する傾向走した。この KCG/C-20の破 断は, 繊維の引き抜けを伴う破壊が進行し, 破断面には 無数の繊維の引き抜けが観察された。KCG/C-250 S$\mathrm{S}$ 曲線は KCG/C- 20 と類似の曲線を示したが, 最大荷 重前の傾きの減少は KCG/C- 20 に比べて少なかった。 

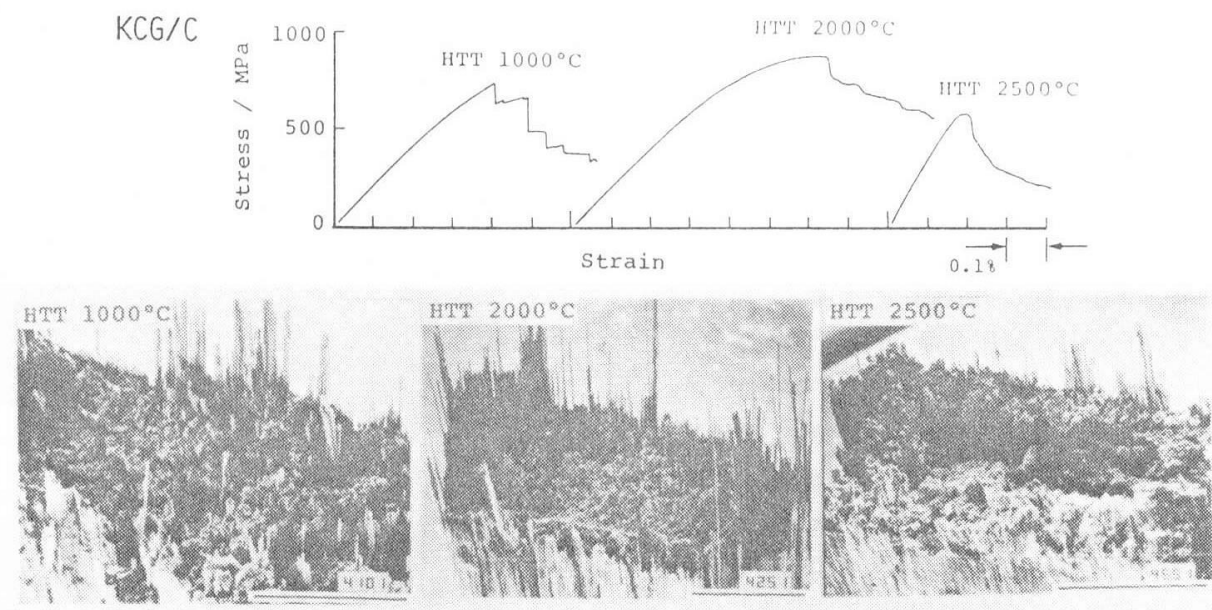

$\mathrm{KC} / \mathrm{C}$
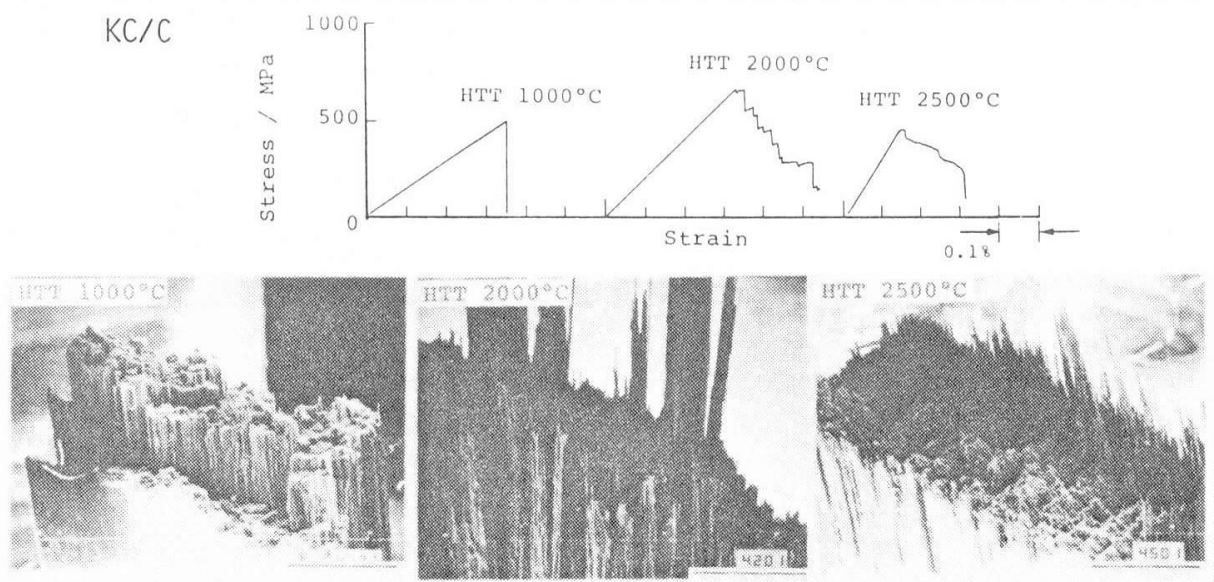

Fig. 2 Stress-strain curves and fractured surfaces by SEM of carbon fiber/carbon composites.

bar: $1 \mathrm{~mm}$

黑鉛微粉末を添加した試料 (KCG/C-10, KCG/C-20) は, 黒鉛微粉末を添加していない同じ熱処理温度の試料 $(\mathrm{KC} / \mathrm{C}-10, \mathrm{KC} / \mathrm{C}-20)$ 上比較し, 最大荷重後に急激 な荷重の低下を示さなかった。黒鉛微粉木を添加するこ とにより, マトリックス組織が改善され，複合材料の脆 性的な破壊が改善されることが分かった。 $\mathrm{KC} / \mathrm{C}-25$ の S-S 曲線が KCG/C- 25 亿類似していたのは, 熱処理温 度が $2500^{\circ} \mathrm{C}$ と高いためマトリックスの黒鉛組織が発達 し, 黒鉛微粉末の添加効果よりも熱処理の効果が大きく 影響したためと考えられる。 $\mathrm{KC} / \mathrm{C}-25 ， \mathrm{KCG} / \mathrm{C}-25$ 之 あに熱处理 $2000^{\circ} \mathrm{C}$ から $2500^{\circ} \mathrm{C}$ の間で弾性率が急激に 増加しており，マトリックス組織が配向したてとを裹付 けている。
䋐維よマトリックスとの接着について，黑鉛微汾末を 添加した効果を検討するため, S-S 曲線の違いが顕著で ある KC/C-10 と KCG/C-10 亿ついて高倍で破断面観 察を行った (Fig. 3)。KC/C-10 は，平滑な破断面を示 し炭素瀻維の引き抜けもほとんど観測されず，亀裂が炭 素䋐維とマトリックスとを同時に切断して進行したてと が分かる。こ机は，炭素繊維とマトリックスとの接着が 強固であることを示している。こ扎対して，KCG/C10 では炭素繊維の引き抜けが観察され，しかす炭素繊維 のみが引き抜けている。マトリックスが炭素繊維に付着 して引き抜けている部分（矢印）ああるが，炭素織維の みが引き抜けている箇所と共存している。ての織維の引 き抜けが，S-S曲線の傾きが緩やかになり，さらに最大 

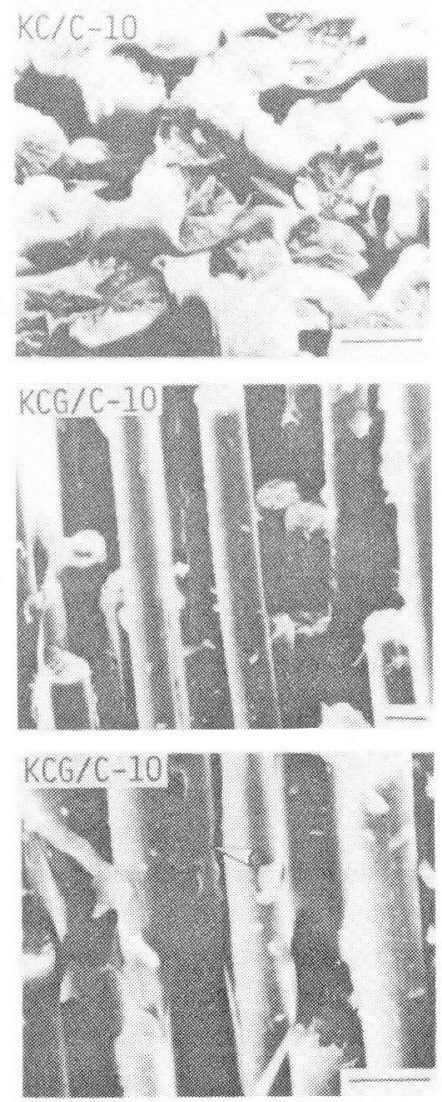

Fig. 3 Fractured micrographs by SEM of $\mathrm{KC} / \mathrm{C}-10$ and $\mathrm{KCG} / \mathrm{C}-10$. bar: $10 \mu \mathrm{m}$
荷重後は荷重が暫減した原因であると考えられる。KCG /C-10では，龟裂はマトリックスを切断しているが，炭 素繊維の主亀裂面内での切断には至っていない。乙机は, KCG/C-10の界面での炭素繊維とマトリックスとの接 着が，KC/C-10 に比較して弱いためと考えられ，炭素 穢維にサイジング剤と其に黒鉛微粉木を塗布するととに より界面接着強度老制御（弱くする方向に）できるとよ を示唆している。

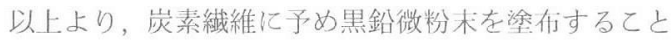
によりマトリックス組織を微細化できること，また界面 での炭素纎維とマトリックスとの接着強度を制御できる とと,さらに黒鉛微粉末塗布繊維を用いた複合材料の強 度は黒鉛微粉末を塗布していない炭素瀻維を用いた複合 材料上りも高くなるととが分かった。

\section{文献}

1) 木村脩七, 安田公一, 安田栄一, 田辺靖博, 炭素 1987 [No. 128] 30

2) 木村脩七, 安田公一, 安田栄一, 田辺靖博, 川村 和郎, 稲垣道夫, 炭素 1986 [No. 125] 62

3) E. Fitzer, W. Huettner and L.M. Manocha, Carbon 18, 291 (1980) 